\title{
Colon biopsies for evaluation of acute graft-versus-host disease (A-GVHD) in allogeneic bone marrow transplant patients
} Vinod B Shidham*1, Chung-Che Chang1, Ganesh Shidham², Farrukh Ghazala1, Paul F Lindholm¹, Bal Kampalath ${ }^{1}$, Varghese George ${ }^{3}$ and Richard Komorowski ${ }^{1}$

Address: ${ }^{1}$ Department of Pathology, Medical College of Wisconsin, Milwaukee, WI, USA, ${ }^{2}$ Division of Nephrology, Medical College of Wisconsin, Milwaukee, WI, USA and ${ }^{3}$ Division of Biostatistics, Medical College of Wisconsin, Milwaukee, WI, USA

Email: Vinod B Shidham* - vshidham@mcw.edu; Chung-Che Chang - jcchang@mcw.edu; Ganesh Shidham - gshidham@hotmail.com; Farrukh Ghazala - meh407@aol.com; Paul F Lindholm - p-lindholm@northwestern.edu; Bal Kampalath - bkampala@mcw.edu; Varghese George - vgeorge@uab.edu; Richard Komorowski - rkomor@mcw.edu

* Corresponding author

Published: 27 March 2003

BMC Gastroenterology 2003, 3:5
Received: 30 December 2002

Accepted: 27 March 2003

This article is available from: http://www.biomedcentral.com/I47I-230X/3/5

(c) 2003 Shidham et al; licensee BioMed Central Ltd. This is an Open Access article: verbatim copying and redistribution of this article are permitted in all media for any purpose, provided this notice is preserved along with the article's original URL.

\begin{abstract}
Background: Proper histomorphological interpretation of intestinal acute graft versus host disease (A-GVHD) associated with allogeneic bone marrow transplantation (BMT) is critical for clinical managaement. However, studies methodically evaluating different histomorphological features of A-GVHD are rare.
\end{abstract}

Methods: Colonic biopsies from 44 allogeneic BMT patients having biopsy-proven cutaneous AGVHD were compared with colon biopsies from 48 negative controls.

Results: A-GVHD showed intra-cryptal apoptosis in $91 \%$ and pericryptal apoptosis in adjacent lamina propria in $70 \%(p<0.002)$. Nonspecific apoptosis along the surface epithelium was observed in all groups with comparable frequency. The number of apoptotic cells in mucosa were approximately four times $(5.3$ per 10 HPF) the negative controls $(p<0.002)$ in A-GVHD group. $48 \%$ of cases with A-GVHD showed decreased number of lymphocytes in lamina propria. Some features, including intraepithelial lymphocytes in surface or crypt epithelium; and neutrophils, eosinophils, and edema in lamina propria, did not demonstrate significant difference in A-GVHD and negative controls. Pericryptal apoptosis, dilated crypts, irregular distribution of crypts, decreased lymphocytes, increased microvessel network, focal fibrosis, presence of muciphages, reactive changes in surface epithelium with mucin depletion, mucosal ulceration, and/or reduced mucosal thickness showed higher association with A-GVHD group.

Conclusions: Intracyptal apoptosis is a reliable indicator of A-GVHD. Its diagnostic significance was improved if intracyptal apoptosis was associated with features which were observed more frequently in A-GVHD group as mentioned above. 


\section{Background}

Acute graft versus host disease (A-GVHD) is a significant cause of morbidity and mortality following allogeneic bone marrow transplantation (BMT). It frequently involves skin, intestinal tract, and liver. The incidence of AGVHD after allogeneic BMT ranges from 30\% to 60\% with skin as the most commonly affected organ often accompanied by intestinal and / or liver involvement [1-4]. Intestinal A-GVHD may manifest as abdominal cramps, ileus, profuse diarrhea, and sometimes bleeding. However, these symptoms are not specific and include broad differential diagnoses such as chemotherapy effect, radiation therapy effect, infections, and side effects of other drugs [5-9]. Furthermore, the histomorphological features of these conditions overlap significantly with A-GVHD. Due to this, interpretation of colonic biopsies for intestinal AGVHD may be a major diagnostic challenge especially for those not conversant with these findings [10]. Only a few studies have statistically evaluated the diagnostic significance of some histopathological features [6]. A-GVHD is treated with immunosuppression which may worsen an underlying infective condition. Thus it is extremely important to diagnose these conditions correctly for proper management.

In addition to other histopathological features described in association with A-GVHD, significance of apoptosis, crypt abscess, and crypt loss has been emphasized [4,1115]. However, the distribution pattern of apoptosis in colonic mucosa in A-GVHD has not been methodically evaluated. Similarly the term 'crypt abscesses' has been used previously in A-GVHD, although it appears to be a misnomer as discussed later. This may lead to confusion with 'crypt abscess' of inflammatory bowel disease. 'Crypt abscess' and 'cryptitis' associated with inflammatory bowel diseases, not been evaluated in intestinal A-GVHD previously, were specifically studied to confirm the misnomer status.

We retrospectively analyzed various histomorphological features in 44 colon biopsies from BMT patients with cutaneous A-GVHD and diarrhea. These were compared with 48 colon biopsies from negative control groups. The goal of this study was to systematically evaluate the diagnostic reliability of various histomorphological features with reference to intestinal A-GVHD.

\section{Methods}

\section{Group Definitions}

The colonic biopsies from 92 patients were evaluated retrospectively using archival material and were divided into three categories (group A- 44, group B- 27, and group C21). Group A included BMT cases with biopsy proven cutaneous A-GVHD. All cases in group A were allogeneic BMT and none received peripheral blood stem cell or cord blood transplantation. They received the same conditioning regimen (cyclophosphamide [Cytoxan], cytosine arabinoside, and total body irradiation). The type of AGVHD prophylaxis used was post-transplatation cyclosporin A. Group B and C included negative controls.

\section{Group A}

Consisted of 44 patients ( 25 males and 19 females, 19 to 59 years of age, mean 41.6 years) with diarrhea and biopsy proven cutaneous A-GVHD. In this group, intestinal AGVHD was strongly favored, in the absence of other etiologies such as CMV colitis and NSAIDs $[2,4,7,9,12,16,17]$. CMV colitis cases were excluded morphologically based on the presence of CMV cytopathic effect or CMV immunohistochemistry. The cases with suspicious features such as ill defined cytopathic changes and ischemic features were also automatically excluded without performing CMV immunohistochemistry to avoid possibility of inclusion of cases with CMV. These 44 colon biopsies were performed 21 to 100 day post-BMT (median 35 days) prior to the commencement of treatment for A-GVHD and within 15 days of A-GVHD positive skin biopsy for investigating their diarrhea.

The underlying indications for BMT in these 44 cases in group A are shown in Table 1. The distribution of cases with reference to the grading of cutaneous A-GVHD included, 20 cases with grade I, 13 with grade II, 5 with grade III, and 6 with grade IV. Published clinical and histological criteria were used to define cutaneous and intestinal A-GVHD [12-14,18,19]. Grading of A-GVHD was not attempted in colon biopsies.

\section{Group B}

(negative control I): Included 27 patients (13 males and 14 females, 20 to 77 years of age, mean 51.5 years) without immunodeficiency, BMT, or any other transplantation. They had non-specific GI symptoms like diarrhoea and abdominal cramps without inflammatory bowel disease. The histopathology was negative for any diagnostic pathology with nonspecific changes or normal colonic mucosa.

\section{Group C}

(negative control II): Included 21 kidney transplant patients (14 males and 7 females, 46 to 75 years of age, mean 60.3 years) with non-specific GI symptoms like diarrhea and guaiac positive stool. The sections of colon biopsies were histopathologically negative for diagnostic pathology. These patients in group $\mathrm{C}$ were under maintainance immunosupressive therapy with cyclosporine or tacrolimus, prednisone, and mycophenalate mofetil. This group was included to study if any of the histomorphological features evaluted in this study have significant 
Table I: Group definitions and demographics of the cases studied.

\begin{tabular}{|c|c|c|c|}
\hline & Group A & Group B & Group C \\
\hline & $\begin{array}{l}\text { Positive group with A-GVHD by skin biopsy*. } \\
\text { Cases of BMT. Underlying indications for BMT are } \\
\text { shown as the foot notes of this table**. } \\
\text { With diarrhea and without identifiable infectious etiology } \\
\text { and history of drugs like NSAIDs, steroids. }\end{array}$ & $\begin{array}{l}\text { Negative control group I. } \\
\text { Without any transplantation and } \\
\text { immunosupresion. } \\
\text { With Gl symptoms like diarrhea, guaiac } \\
\text { positive stool. }\end{array}$ & $\begin{array}{l}\text { Negative control group II. } \\
\text { With kidney transplantation**** } \\
\text { With GI symptoms like diarrhea, guaiac } \\
\text { positive stool. }\end{array}$ \\
\hline \multicolumn{4}{|c|}{ 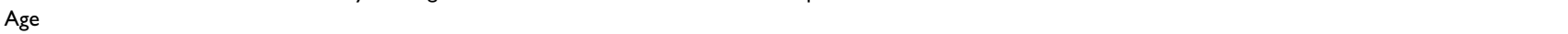 } \\
\hline Mean & 41.6 years & 51.5 years & 60.3 years \\
\hline SD & 9.2 & 12.5 & 8 \\
\hline Range & 19 to 59 years & 20 to 77 years & 46 to 75 years \\
\hline \multicolumn{4}{|l|}{ Sex } \\
\hline Males & 25 & 13 & 14 \\
\hline Females & 19 & 14 & 7 \\
\hline Total & $44^{*}$ & 27 & 21 \\
\hline
\end{tabular}

*The splitting of total cases according to the grading of cutaneous A-GVHD: Grade I- 20, Grade II- 13, Grade III- 5, Grade IV- 6. **The diagnoses for which BMT was done includes: Hodgkin's Lymphoma (3), Non-Hodgkin's Lymphoma (4), T-cell Lymphoblastic Lymphoma (5), IgG Multiple myeloma (3), Plasma cell leukemia (I), Chronic Myelogenous Leukemia ( I7), Chronic myelomonocytic Leukemia (2), Myelodysplastic syndrome (I), and Others (8). All cases received the same conditioning regimen (cyclophosphamide [Cytoxan], cytosine arabinoside, and total body irradiation). The type of A-GVHD prophylaxis used was post-transplatation cyclosporin A. ****The duration of kidney transplantation ranged from 8 to 64 months (mean 28 months).

relationship with transplantation in general including effect of immunosupressive therapy.

Subclinical A-GVHD in the absence of cutaneous AGVHD or gastrointestinal symptoms is known $[4,10]$. Because of this reason a fourth hypothetical control group of biopsies from BMT patient without A-GVHD though desired was considered impractical, as various criteria under scrutiny in this study will be deciding if those biopsies would have to be considered negative for A-GVHD. Other negative control group desired would be colonic biopsies from the cases undergoing all the therapy components of BMT including cytoreductive therapy but without BMT. However, such a group would also be impractical during any clinical study due to obvious ethical limitations. Autologous BMT case without cyclosporine induced GVHD or viral infection would have been ideal control $[28,29]$. However, due to limited number of cases in this group we could not include such a group.

Histomorphological features secondary to the effects of non-steroidal anti-inflammatory drugs (NSAIDs) $[4,7]$ and intestinal infections, especially cytomegalovirus (CMV) $[2,9,12,16,17]$ are known to overlap with AGVHD. Due to this, based on clinical details, the cases with such associations were excluded from this study.

\section{General information}

Polyethylene glycol solution (GoLytely ${ }^{\circledR}$, Braintree Laboratories, Braintree, MA) was used for endoscopic preparation in all the groups. Due to known subtle differences between left and right side of the colon, the proportion of different sites in each group was matched for statistical correction. All colon biopsies were fixed in Bouin's fixa- tive and processed routinely. Multiple levels of paraffinembedded tissue sections stained with H\&E were examined in blinded fashion without knowing the category.

\section{Histopathological Analysis}

Various histological features important for the differential diagnosis of A-GVHD were selected after review of literature [12-14]. All H\&E stained sections were evaluated qualitatively or semi-quantitatively for histomorphological features shown in table 2.

The mucosal thicknesses (Table 2, A) from the surface epithelium to the internal limit of muscularis mucosa in three places were measured in the area of least thickness and mean was calculated. Thickness $>500$ microns was considered within normal limits [20]. Cryptitis and crypt abscess were defined respectively as infiltration of crypt epithelium with neutrophils and presence of neutrophils in crypt lumen (Table 2, F). Five or fewer intraepithelial lymphocytes per 100 epithelial cells in surface and crypt lining were considered to be within normal limits (Table 2, G and H) [21]. We classified 1-5 extravascular neutrophils per 20 inflammatory cells in the lamina propria (LP) as mild increase and more than five as marked increase (Table 2, L). Macrophages with mucin as faintly basophilic foamy cytoplasm in H\&E stained sections were identified as muciphages. Five or more muciphages in LP per 10 crypts were considered significant (Table 2, P). Presence of five or more endothelial lined blood spaces larger than 50 microns for every 10 crypts was regarded as increased microvessel network (Table 2, Q). Apoptosis (defined as single cell death) was indentified in $\mathrm{H} \& \mathrm{E}$ stained sections as apoptotic cells with scattered karyorrhectic basophilic globular intracytoplasmic debris of ap- 


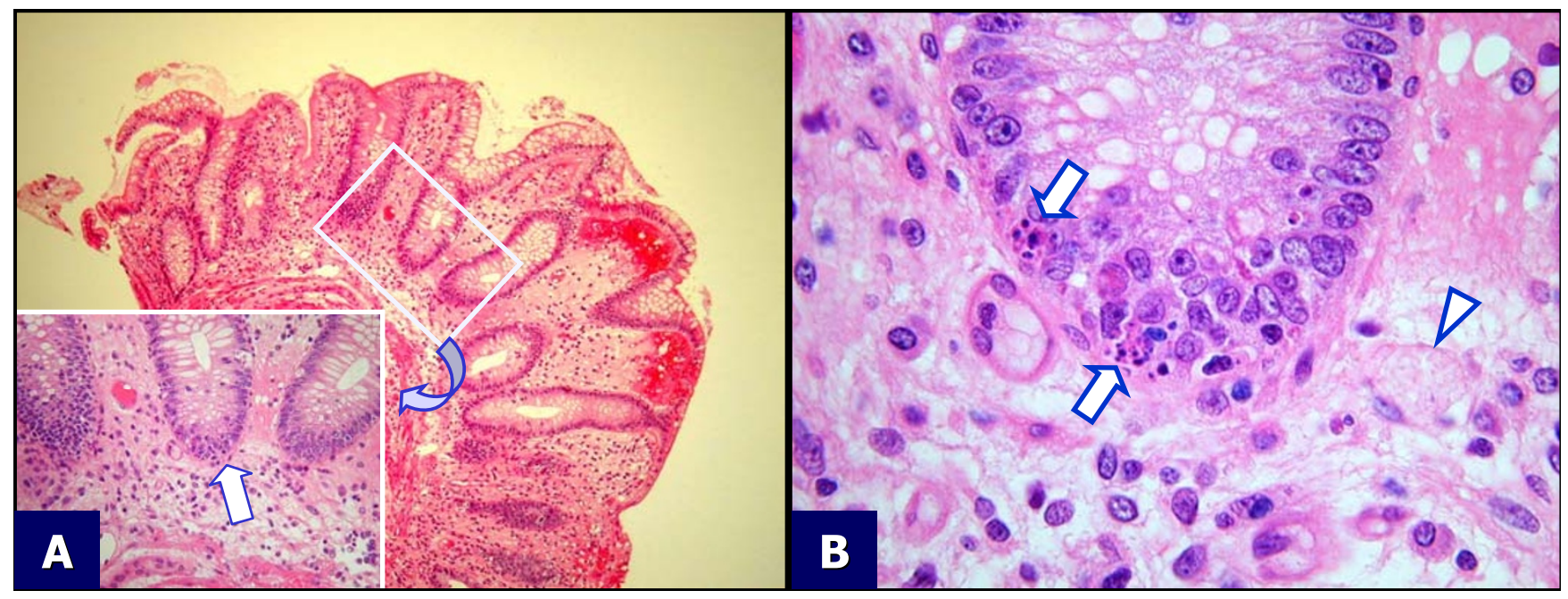

\section{Figure I}

Colonic biopsy with GVHD. A. Colonic mucosa with apoptotic bodies in crypts. Inset- Crypts show many apoptotic bodies (for higher magnification of the crypt with arrow see figure IB). B. Magnified crypt shown in the inset of figure IA: The crypt shows "popcorn" lesions (arrows) with occasional muciphages (arrowhead) in LP.

optotic bodies (Figure 1). Apoptotic cells were counted in 10 high power field (HPF) at $40 \times$ magnification with a field diameter of $0.35 \mathrm{~mm}$. Mitotic figures were counted per 10 crypts (Table 3 ).

\section{Statistical Analysis}

Each group was evaluated for the frequency of various histomorphological features shown in table 2. The findings in group A were compared with groups $\mathrm{B}$ and $\mathrm{C}$ using Fisher's exact test (Table 2). Number of apoptotic cells and mitotic figures in group A were compared with those in groups B and C using Wilcoxan Rank Sum Test (Table 3).

In order to compensate for the multiple testing and thus to avoid imparting spurious significance, we used a stringent significance level of 0.002 for each test. This was based on the Bonferroni correction factor for multiple testing to achieve an overall significance level of 5\% [22]. Histomorphological features with statistically significant differences were separated for further analysis (Table 4).

\section{Results}

The comparative frequency of various histomorphological features observed in all the three groups is shown in table 2. Apoptosis in crypt lining was associated with higher frequency in A-GVHD with statisticaaly significant difference (Table 3 and 4). Other features observed more often in AGVHD with statistically significant differences as compared to the negative control groups included (Table 2 and 4, Figure 2): pericryptal apoptosis adjacent to the crypts in LP, crypt abnormalities (including crypt size variation, crypt dilatation and irregular crypt distribution), 
Table 2: Comparison of histological features in group A with A-GVHD and negative controls in group B \& C.

\begin{tabular}{|c|c|c|c|c|c|}
\hline \multirow{3}{*}{\multicolumn{3}{|c|}{ Histological features evaluated }} & \multicolumn{3}{|c|}{ Frequency of the histological features in $\%$} \\
\hline & & & \multirow[b]{2}{*}{ A-GVHD Grp A $(n=44)$} & \multicolumn{2}{|l|}{ Negative control } \\
\hline & & & & Grp B $(n=27)$ & Grp C $(n=21)$ \\
\hline A & \multicolumn{2}{|l|}{ Reduced mucosal thickness } & $47.73 \%$ & $0.00 \% *$ & $0.00 \% *$ \\
\hline B & \multicolumn{2}{|l|}{ Mucosal ulceration } & $27.27 \%$ & $0.00 \% *$ & $0.00 \% *$ \\
\hline C & \multicolumn{2}{|c|}{ Reactive changes in superficial epithelium } & $41.86 \%$ & $0.00 \% *$ & $0.00 \% *$ \\
\hline$D_{1}$ & & Size variation & $97.73 \%$ & $29.63 \% *$ & $14.28 \% *$ \\
\hline$D_{2}$ & Crypt abnormalities & Irregular distribution & $63.64 \%$ & $3.70 \% *$ & $0.00 \% *$ \\
\hline$D_{3}$ & & Crypt dropout & $30.23 \%$ & $0.00 \% *$ & $0.00 \% *$ \\
\hline $\mathrm{E}$ & \multicolumn{2}{|l|}{ Crypt dilatation } & $72.73 \%$ & $3.70 \% *$ & $0.00 \% *$ \\
\hline $\mathrm{F}$ & \multicolumn{2}{|l|}{ Cryptitis and crypt abscess } & $2.27 \%$ & $0.00 \%$ & $4.76 \%$ \\
\hline G & \multicolumn{2}{|c|}{$\begin{array}{l}\text { Increased intraepithelial lymphocytes in superficial epithe- } \\
\text { lium }\end{array}$} & $6.98 \%$ & $0.00 \%$ & $0.00 \%$ \\
\hline $\mathrm{H}$ & \multicolumn{2}{|c|}{ Increased intraepithelial lymphocytes in crypts } & $6.98 \%$ & $0.00 \%$ & $0.00 \%$ \\
\hline I & \multicolumn{2}{|c|}{ Intraepithelial neutrophils in superficial epithelium } & $9.30 \%$ & $0.00 \%$ & $0.00 \%$ \\
\hline J & \multicolumn{2}{|c|}{ Intraepithelial neutrophils in crypts } & $6.82 \%$ & $0.00 \%$ & $0.00 \%$ \\
\hline $\mathrm{K}_{\mathrm{I}}$ & \multirow{4}{*}{ Distribution of apoptosis } & Intraepithelial in SE & $76.74 \%$ & $77.78 \%$ & $57.4 \%$ \\
\hline $\mathrm{K}_{2}$ & & Intracryptal ("popcorn") & $90.91 \%$ & $11.11 \% *$ & $14.28 \% *$ \\
\hline $\mathrm{K}_{3}$ & & Lamina propria, near SE & $79.55 \%$ & $70.37 \%$ & $85.7 \%$ \\
\hline $\mathrm{K}_{4}$ & & Pericryptal & $70.45 \%$ & $22.22 \% *$ & $4.76 \% *$ \\
\hline $\mathrm{L}_{0}$ & \multirow{3}{*}{$\begin{array}{l}\text { Neutrophils in lamina } \\
\text { propria }\end{array}$} & None & $59.09 \%$ & $74.07 \%$ & $57.14 \%$ \\
\hline$L_{1}$ & & Marked increase & $4.55 \%$ & $18.52 \%$ & $00.00 \%$ \\
\hline $\mathrm{L}_{2}$ & & Mild increase & $36.36 \%$ & $11.11 \%$ & $42.85 \%$ \\
\hline$M_{0}$ & \multirow[t]{2}{*}{$\begin{array}{l}\text { Eosinophils in lamina } \\
\text { propria }\end{array}$} & Few to none & $100 \%$ & $96.30 \%$ & $100.00 \%$ \\
\hline$M_{1}$ & & many & $0.00 \%$ & $3.70 \%$ & $0.00 \%$ \\
\hline $\mathrm{N}$ & \multicolumn{2}{|l|}{ Focal periglandular infiltrate } & $6.98 \%$ & $0.00 \%$ & $0.00 \%$ \\
\hline$O_{1}$ & Edema in lamina propria & Focal & $86.36 \%$ & $88.88 \%$ & $28.57 \%$ \\
\hline $\mathrm{O}_{2}$ & & Diffuse & $4.55 \%$ & $0.00 \%$ & $0.00 \%$ \\
\hline
\end{tabular}


Table 2: Comparison of histological features in group A with A-GVHD and negative controls in group B \& C. (Continued)

\begin{tabular}{|c|c|c|c|c|}
\hline $\mathrm{P}$ & Muciphages in lamina propria & $43.18 \%$ & $0.00 \% *$ & $4.76 \% *$ \\
\hline Q & $\begin{array}{l}\text { Increased microvessel } \\
\text { network in lamina } \\
\text { propria }\end{array}$ & $61.36 \%$ & $0.00 \% *$ & $0.00 \% *$ \\
\hline $\mathrm{R}$ & Clusters of enterochromaffin cells & $0.00 \%$ & $0.00 \%$ & $0.00 \%$ \\
\hline$S_{1}$ & Fibrosis in lamina propria & $47.73 \%$ & $0.00 \% *$ & $0.00 \% *$ \\
\hline$S_{2}$ & Diffuse & $2.27 \%$ & $0.00 \%$ & $0.00 \%$ \\
\hline
\end{tabular}

$\mathrm{n}$, total number of cases in a group; SE, surface epithelium. * Statistically significant difference with $\mathrm{p}$ values less than 0.002 with Fisher's exact test when $A$ was compared with $B$ and $C$ individually.

Table 3: The comparison of frequencies of apoptotic cells and mitotic figures in colon biopsies.

\begin{tabular}{|c|c|c|c|c|}
\hline & & \multirow[b]{2}{*}{ Group A } & \multicolumn{2}{|c|}{ Negative controls } \\
\hline & & & Group B & Group C \\
\hline \multirow{3}{*}{$\begin{array}{l}\text { Number of apoptotic cells (per } 10 \mathrm{HPF}, \mathrm{X} 40 \text {, } \\
\text { FD- } 0.35 \mathrm{~mm} \text { ). }\end{array}$} & Mean & $5.29 *$ & $1.25^{*}$ & $1.42 *$ \\
\hline & Range & I to 50 & 0 to 3 & I to 3 \\
\hline & SD & 8.49 & 0.90 & 0.60 \\
\hline \multirow{3}{*}{$\begin{array}{l}\text { Number of mitotic figures in crypt lining (per } \\
10 \text { crypts). }\end{array}$} & Mean & 2.65 & 1.88 & 2.28 \\
\hline & Range & 1 to 10 & I to 5 & I to 7 \\
\hline & $S D$ & 1.98 & 1.01 & 1.80 \\
\hline
\end{tabular}

SD, standard deviation; HPF, high power field, FD, field diameter. *Statistically significant differences between Group A / B and Group A / C respectively. The $p$ values calculated by Wilcoxan Rank Sum Test were less than 0.002 .

reactive changes in LP (including reduced mucosal thickness, muciphages in LP, increased microvessel network, and focal fibrosis), and reactive changes in the surface epithelium with mucin depletion.

Apoptosis in crypt lining was observed in $91 \%$ of group A cases with A-GVHD and demonstrated statistically significant difference as compared to negative control group B and C ( $p<0.002$, Fisher's exact test) (Table $2 \mathrm{~K}_{2}$, Figure 1$)$. In group A, $70 \%$ of cases showed apoptotic cells in LP around the crypts as compared to $22 \%$ in group B and 5 $\%$ in group $\mathrm{C}(\mathrm{p}<0.002)$ (Table $\left.2 \mathrm{~K}_{4}\right)$. Apoptosis in the surface epithelium did not show any significant difference between the three groups (Table $2 \mathrm{~K}_{1}$ ). Apoptotic bodies in LP adjacent to the surface epithelium were also nonspecific and did not show significant difference between the three groups (Table $2 K_{3}$ ). An average 5.3 apoptotic cells per $10 \mathrm{HPF}$ were observed in group $\mathrm{A}$, in contrast to only 1.25 in group B and 1.42 in group C $(\mathrm{p}<0.002$, Wilcoxan Rank Sum Test) (Table 3).
Intraepithelial lymphocytes and neutrophils in the surface epithelium and the crypt epithelium did not show statistically significant difference in A-GVHD group and negative controls (Table 2, G,H,I,J). Neutrophils, eosinophils, and edema in LP were nonspecific and were observed with comparable frequencies in all the three categories (Table $2, \mathrm{~L}, \mathrm{M}, \mathrm{O})$. The number of mitotic figures in crypt lining did not show statistically significant difference between the three groups (Table 3).

\section{Discussion}

Some of the histological features of A-GVHD in colonic biopsies have been studied and reported previously $[6,11,14,23]$. But they have not been evaluated together as collective features with methodical statistical analysis. Crypt cell apoptosis has been described as a significant finding in intestinal A-GVHD. Usually this is focal in nature and results in membrane bound debris of apoptotic bodies in the crypts. This phenomenon has been labeled variously as "exploding crypt cells" [13,24], "karyolytic body $[1,12,14]$, "apoptotic body" $[1,12]$, "granular necrosis", [2] and "popcorn lesions" [2,13] (Figure 1). Though 


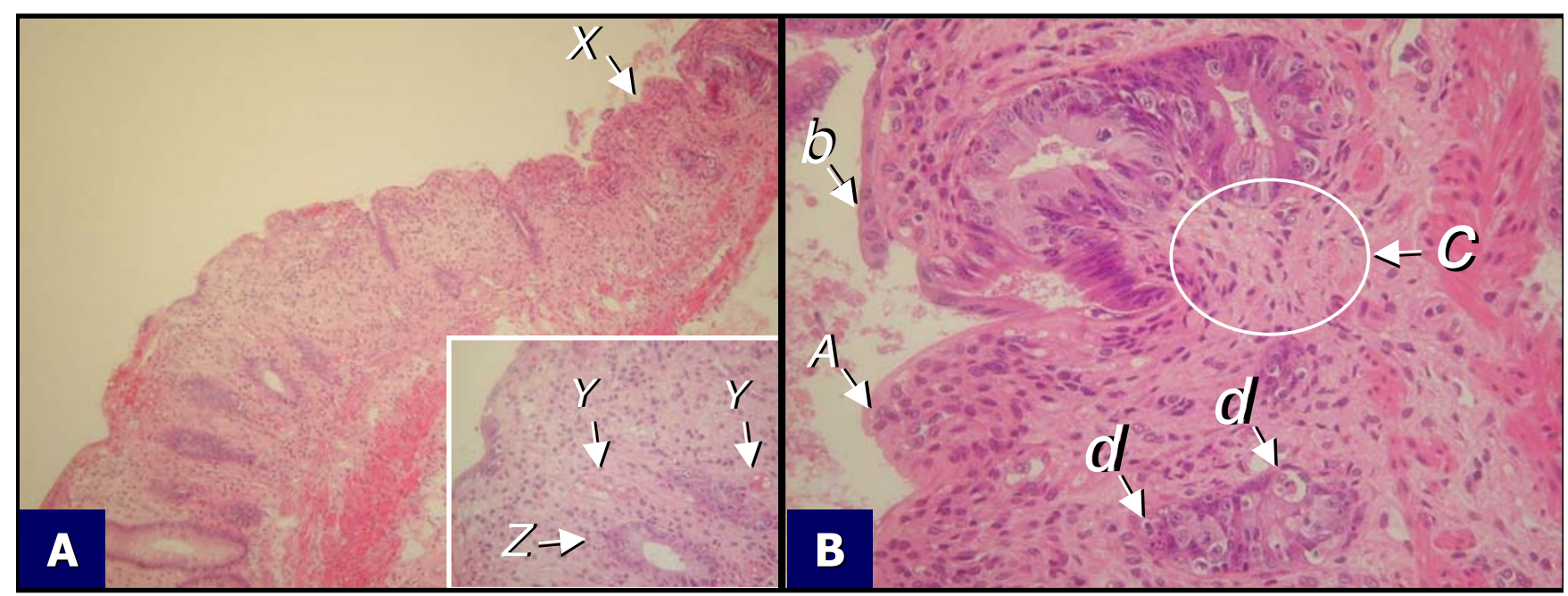

\section{Figure 2}

A. Colonic biopsy with GVHD- Focal crypt abnormalities (crypt size variation and irregular crypt distribution) with decreased mucosal thickness $(x)$. Inset: Ectatic vessels $(y)$ and slightly dilated crypt $(z)$ with mild decrease in number of lymphocytes in LP. B. Colonic biopsy with GVHD (higher magnification of area adjacent to ' $x$ ' in figure $2 A$ ) - Crypt abnormalities with focal ulceration $(A)$, focal reactive surface epithelium $(b)$, focal fibrosis $(C)$, and many apoptotic cells in crypts $(d)$.

this lesion is not specific for A-GVHD, it is a cardinal feature as demonstrated by experimental production of intestinal A-GVHD in the Rhesus monkey [14,25]. It is a valuable diagnostic feature in the absence of infections especially CMV $[2,4,7,9,12,16,17]$. Other critical differential diagnoses include effects of radiation-chemotherapy $[12,13]$ and effects of other drugs such as NSAIDs [7].

A higher number of apoptotic bodies were observed in AGVHD than in negative controls (Table 3). The distribution pattern of apoptosis in colon biopsies with AGVHD has not been evaluated previously with statistical analysis. In this study, a statistically significant difference was noted when the distribution of apoptotic bodies in crypts and around the crypts was compared with those in surface epithelium and adjacent to the surface epithelium.

The frequency of apoptotic bodies in surface epithelium and adjacent LP in all the three groups were comparable and did not show statistically significant difference (Table $2, \mathrm{~K}_{1}$ and $\mathrm{K}_{3}$ ). The presence of apoptosis in surface epithelium or in adjacent LP is nonspecific. In the absence of apoptosis in the crypts, presence of apoptosis along the surface epithelium does not have any diagnostic significance for A-GVHD. The cause of apoptosis along the surface epithelium is physiological turnover with loss from the surface epithelium and the replacement by proliferation of cells in the crypts. Variety of non-specific factors may accelerate this with increased number of apoptotic cells along the surface epithelium.

As compared to the negative controls (group B- 11\% and group C-14\%), crypt apoptosis was frequent in A-GVHD$91 \%$ with statistically significant difference (Table $2 \mathrm{~K}_{2}$ ). With proper clinical history, the diagnosis of A-GVHD can be suggested if apoptosis is observed in and around the crypts. Association of cryptal apoptosis with other features (Table 4) should increase the diagnostic accuracy. These associations included reactive changes in the surface epithelium, increased muciphages, reduced mucosal thickness, focal fibrosis in LP, irregular distribution of crypts, crypt dilatation, and crypt size variation (Table 4). However, some of these features may be secondary to cytoreductive therapy and other components of BMT. In general, the effects of cytoreductive therapy are not observed after 20 days [12]. Under proper clinical situation, 
Table 4: Summary of diagnostically significant morphological features associated with intestinal A-GVHDI.

\begin{tabular}{|c|c|c|c|c|c|c|c|c|c|c|}
\hline \multirow[t]{2}{*}{ S. No } & \multirow[t]{2}{*}{ Findings } & & \multicolumn{2}{|c|}{$\begin{array}{l}\text { A-GVHD cases Group A } \\
n=44\end{array}$} & \multicolumn{2}{|c|}{$\begin{array}{l}\text { Negative controles } \\
(B+C)^{*} n=48\end{array}$} & \multirow[t]{2}{*}{ Sp } & \multirow[t]{2}{*}{ Sn } & \multirow[t]{2}{*}{ PPV } & \multirow[t]{2}{*}{ NPV } \\
\hline & & & TP & $\mathrm{FN}$ & $\mathrm{TN}$ & $\mathrm{FP}$ & & & & \\
\hline \multirow[t]{2}{*}{ I. } & Apoptosis & $\left(\mathrm{K}_{2}\right)$ Apoptosis in crypt lining & 40 & 4 & 42 & 6 & 87 & 91 & 93 & 91 \\
\hline & & $\begin{array}{l}\text { (K4) Pericryptal apoptosis in LP, adjacent } \\
\text { to the crypts }\end{array}$ & 31 & 13 & 41 & 7 & 85 & 70 & 84 & 93 \\
\hline \multirow[t]{3}{*}{2.} & $\begin{array}{l}\text { Crypt } \\
\text { abnormalities }\end{array}$ & $\left(D_{1}\right)$ Crypt size variation & 43 & 1 & 37 & 11 & 77 & 98 & 100 & 97 \\
\hline & & (E) Crypt dilatation & 32 & 12 & 47 & 1 & 98 & 73 & 97 & 80 \\
\hline & & $\left(D_{2}\right)$ Irregular distribution of crypts & 28 & 16 & 47 & 1 & 98 & 64 & 97 & 75 \\
\hline \multirow[t]{5}{*}{3.} & $\begin{array}{l}\text { Reactive } \\
\text { changes a. In } \\
\text { lamina propria }\end{array}$ & (R) Increased LP microvascular network & 27 & 17 & 48 & 0 & 100 & 61 & 100 & 74 \\
\hline & & $\left(T_{1}\right)$ Focal fibrosis in LP & 21 & 23 & 46 & 2 & 96 & 48 & 100 & 67 \\
\hline & & (A) Reduced mucosal thickness & 21 & 23 & 48 & 0 & 100 & 48 & 100 & 68 \\
\hline & & (Q) Muciphages in LP & 18 & 26 & 42 & 6 & 87 & 41 & 100 & 62 \\
\hline & $\begin{array}{l}\text { b. In surface } \\
\text { epithelium }\end{array}$ & (C) Reactive changes in SE & 18 & 26 & 48 & 0 & 100 & 41 & 100 & 65 \\
\hline
\end{tabular}

IMorphological features demonstrating statistically significant association with A-GVHD (selected from Table 2). *Addition of Group B (27) and Group C (2I). Due to the lack of ideal but practical negative control (as discussed in the text), sensitivities and specificities calculated in this study are based on the practical negative controls in group B and C. TP, true positive; FN, false negative; TN, true negative; FP, false positive, LP, lamina propria, SE, surface epithelium. Sp, Specificity; Sn, Sensitivity; PPV, Positive predictive value; NPV, Negative predictive value.

their association with apoptosis in crypts and pericryptal apoptosis in LP is consistent with A-GVHD in BMT. Further evaluation of these features in relation to individual components of BMT protocols may be conducted as animal experiments with proper controls. As mentioned under materials and methods, such evaluation would be impractical as clinical study due to obvious ethical limitations in organizing proper controls.

Patients with cutaneous and hepatic A-GVHD frequently have apoptosis in their colon biopsies, without any intestinal symptoms [4]. This may represent sub-clinical intestinal A-GVHD if the apoptosis is observed in relation to the crypts [10]. If other findings (Table 4) are present in the absence of crypt apoptosis, it may represent evidence of past A-GVHD or due to other etiologic factors such as chronic infections and inflammatory bowel disease.

As noted in this study, classical cryptitis with infiltration of crypt-lining by neutrophils and crypt abscesses with neutrophils within crypt lumens observed in inflammatory bowel disease were not features of intestinal A-GVHD (Table 2, F). 'Cryptitis' has been described in association with A-GVHD, but these studies do not define the term $[6,12,13]$. Although reference had been made to crypt abscesses in these reports, it is evident that the researchers were looking at the apoptotic debris in gland lumina and suggested 'crypt abscess-like' changes [14]. In our study, only one case $(2.7 \%)$ from group A with A-GVHD showed occasional crypt abscess (Table 2) and this may represent a coincidental inflammatory bowel disease - like damage [26]. Mild cryptitis with a few crypt abscesses was also ob- served in one patient $(4.76 \%)$ in group C with kidney transplantation (Table 2). Thus, classical cryptitis and crypt abscesses with infiltration of crypt lining and crypt lumen with neutrophils observed in inflammatory bowel disease is not a feature of A-GVHD.

A change, that was called focal periglandular infiltrate by Bombi et al [6], was observed by us in three $(6.9 \%)$ cases of A-GVHD involving only one or two crypts (Table 2, N). Sale and colleagues described a comparable feature with "focal increase in density of lymphocytes, plasma cells, and occasional eosinophils in the LP" [13]. This finding was suggested as a marker for apoptosis favoring the clinical diagnosis of A-GVHD [6]. They have suggested that the presence of focal periglandular infiltrate warrants a careful search for cryptal apoptosis. We did not observe this finding in negative control groups $\mathrm{B}$ and $\mathrm{C}$.

The clusters of enterochromaffin cells in A-GVHD have been reported previously $[25,27]$. They have been described in association with apoptosis, suggesting their presence as the result of selective sparing of enterochromaffin elements during the process of A-GVHD. We did not observe them in H\&E stained sections (Table 2, R).

\section{Conclusions}

Apoptosis in crypt lining and pericryptal apoptosis adjacent to crypts in LP, especially when associated with the features such as crypt abnormalities and reactive changes in mucosa (LP and surface epithelium) favor the diagnosis of A-GVHD. Cryptitis and crypt abscesses are not feature of A-GVHD and should be differentiated from "popcorn 
lesions", which show apoptotic cells instead of neutrophils along the crypt lining and in the crypt lumen.

\section{List of abbreviations}

A-GVHD, Acute graft-versus-host disease; BMT, bone marrow transplantation; LP, lamina propria; H\&E, hematoxylin and eosin.

\section{Competing interests}

None declared.

\section{Authors' contributions}

VS conceived, designed, and carried out the entire study in addition to the drafting of manuscript. CC participated in the design of the study and performed the statistical analysis. GB participated in the design of the study and contributed data on negative controls in kidney transplant group. FG participated in the design of the study and assisted in data collection. PF, BK, and RK all participated in its design and coordination. VG performed the statistical analysis. All authors read and approved the final manuscript.

\section{Acknowledgments}

Authors thank Dan Eastwood, MS for the statistical analysis of the data during this study. We also thank Sushrut Shidham and Patsy Gill for the secretarial assistance.

\section{References}

I. McDonald GB, Shulman HM, Sullivan KM and Spencer GD Intestinal and hepatic complications of human bone marrow transplantation: Part I Gastroenterology 1986, 90:460-477

2. McDonald GB, Shulman HM, Sullivan KM and Spencer GD Intestinal and hepatic complications of human bone marrow transplantation: Part II Gastroenterology 1986, 90:770-784

3. Rozman C, Granena A, Carreras E, Marin P, Martin E, Palou J, Mascaro JM and Bruguera $M$ [Graft versus host disease. Analysis of I3I cases of bone marrow transplant] [Article in Spanish] Med Clin (Barc) 1 987, 89:89-94

4. Epstein RJJ, Mc Donald GB, Sale GE, Shulman HM and Thomas ED The diagnostic accuracy of the rectal biopsy in acute graftver-sus-host disease: A prospective study of 13 patients Gastroenterology 1980, 78:764-77I

5. Bombi JA, Cardesa A, Llebaria C, Rives A, Carreras E, Granena A and Jimenez de Anta MT Main autopsy findings in bone marrow transplant patients Arch Pathol Lab Med I987, I I I: I 25- I29

6. Bombi JA, Nadal A, Carreras E, Ramirez J, Munoz J, Rozman C and Cardesa A Assesment of histopathologic changes in the colon biopsies in acute graft-versus-host disease Am J Clin Pathol I995, 103:690-695

7. Lee FD Importance of apoptosis in the histopathology of drug related lesions in the large intestine J Clin Pathol 1993, 46: I 18122

8. Schwartz DA and Wilcox CM Atypical cytomegalovirus inclusions in gastrointestinal biopsy specimens from patients with the acquired immunodeficiency syndrome: Diagnostic role of in situ nucleic acid hybridization Hum Pathol 1992, 23:10191026

9. Snover DC Mucosal damage simulating acute graft-versushost reaction in cytomegalovirus colitis Transplantation 1985, 39:669-670

10. Sviland L, Pearson ADJ and Hamilton PJ Diagnosis of acute graftversus-host disease using skin and rectal biopsies In Transplant Pathology (Edited by: Kolbeck RC, Markin RS, McManus BM) ASCP Press, Chicago, IL 1994, 293-307
II. Bombi JA, Palou J, Bruguera M, Feliu E, Martin-Ortega E, Rozman C and Cardesa A Pathology of bone marrow transplantation Semin Diagn Pathol 1992, 9:220-231

12. McDonald GB and Sale GE The human gastrointestinal tract after allogeneic marrow transplantation In: The Pathology of Bone Marrow Transplantation (Edited by: Sale GE, Shulman HM) New York: Masson 1984, 77-103

13. Sale GE, Mc Donald GB, Shulman HM and Thomas ED Gastrointestinal graft-versus-host disease in man: A clinicopathologic study of the rectal biopsy Am J Surg Pathol 1979, 3:291-299

14. Slavin RE and Woodruff JM The pathology of bone marrow transplantation In: Pathology Annual (Edited by: Sommers SD) New York: Appleton-Century-Crofts 1974, 29I-344

15. Woodruff JM, Hansen JA, Good RA, Santos GW and Slavin RE The pathology of the graft-versus-host reaction (GVHR) in adults receiving bone marrow transplants Transplant Proc 1976, 8:675684

16. Lee EY, Clouse RE, Aliperti G and De Schryver K Small intestinal lesion resembling graft-versus-host disease Arch Pathol Lab Med | 99|, I | 5:529-532

17. Sviland L, Pearson ADJ, Green MA, Eastham EJ, Hamilton PJ, Proctor SJ and Malcolm AJ Prognostic importance of histological and immunopathological assessment of skin and rectal biopsies in patients with GVHD Bone Marrow Transplant 1993, I I:2 I 5-2 I8

18. Lerner KG, Kao GF, Storb R, Buckner CD, Clift RA and Thomas ED Histopathology of graft-vs.-host reaction (GvHR) in human recipients of marrow from HL-A-matched sibling donors Transplant Proc 1974, 6:367-371

19. Massi D, Franchi A, Pimpinelli N, Laszlo D, Bosi A and Santucci M A reappraisal of the histopathologic criteria for the diagnosis of cutaneous allogeneic acute graft-vs-host disease Am J Clin Pathol 1999, I I 2:79I-800

20. Fenoglio-Preiser CM, Noffsinger AE, Stemmermann GN, Lantz PE, Listrom MB and Rilke FO The Normal Anatomy of the Colon In: Gastrointestinal Pathology: An Atlas and Text Philadelphia: Lippincott Raven 1999, 747-76।

21. Fenoglio-Preiser CM, Noffsinger AE, Stemmermann GN, Lantz PE, Listrom MB and Rilke FO The Nonneoplastic Lesions of the CoIon In: Gastrointestinal Pathology: An Atlas and Text Philadelphia: Lippincott - Raven 1999, 763-908

22. Pagano $M$ and Gauvreau K Multiple Comparisons Procedures In: Principles of Biostatistics Duxbury Thomson Learning, Pacific Grove, CA 2000, 292-294

23. Sviland L, Pearson AD, Eastham EJ, Hamilton PJ, Proctor SJ and Malcolm AJ Histological features of skin and rectal biopsy specimens after autologous and allogeneic bone marrow transplantation J Clin Pathol 1988, 4I:148-I54

24. Lampert IA, Thorpe P, van Noorden S, Marsh J, Goldman JM, Gordon-Smith EC and Evans DJ Selective sparing of enterochromafin cells in graft versus host disease affecting the colonic mucosa Histopathology 1985, 9:875-886

25. Woodruff JM, Eltringham JR and Casey HW Early secondary disease in the Rhesus monkey. I. A comparative histopathologic study Lab Invest 1969, 20:499-5 I I

26. Carpenter HA and Talley NJ The importance of clinicopathological correlation in the diagnosis of inflammatory conditions of the colon: histological patterns with clinical implications Am J Gastroenterol 2000, 95:878-896

27. Desperbasques $M$, Dhillon $A$ and Hamid $Q$ Epithelial changes following bone marrow transplantation: Cytological atypia and epithelial endocrine cells APMIS 1991, 99:557-566

28. Karasuno $T$ Autologous graft-versus-host disease [Review] International Journal of Hematology. 1997, 65:105-II3

29. Hess AD, Thoburn C], Chen W and Horwitz LR Complexity of effector mechanisms in cyclosporine-induced syngeneic graftversus-host disease Biol Blood Marrow Transplant 2000, 6: I 3-24

\section{Pre-publication history}

The pre-publication history for this paper can be accessed here:

http://www.biomedcentral.com/1471-230X/3/5/prepub 